\title{
Nonparametric decision tree: The impact of ISO 9000 on certified and non certified companies
}

\author{
Joaquín Texeira Quirós ${ }^{1}$, José Figueiredo Almaça ${ }^{2}$, Maria do Rosário Fernandes Justino ${ }^{3}$ \\ ${ }^{1}$ University of Extremadura (Spain) University Autónoma of Lisbon (Portugal) \\ ${ }^{2}$ University Autónoma of Lisbon SOCIUS-ISEG-Technical-University of Lisbon (Portugal) \\ ${ }^{3}$ ISCAL, Polytechnical Institute of Lisbon SOCIUS-ISEG- Technical-University of Lisbon
}

(Portugal)

jtexeira@unex.es, jalmaca@universidade-autonoma.pt, mrjustino@iscal.ipl.pt

Received: October 2011

Accepted: November 2012

\section{Abstract}

Purpose: This empirical study analyzes a questionnaire answered by a sample of ISO 9000 certified companies and a control sample of companies which have not been certified, using a multivariate predictive model. With this approach, we assess which quality practices are associated to the likelihood of the firm being certified.

Design/methodology/approach: We implemented nonparametric decision trees, in order to see which variables influence more the fact that the company be certified or not, i.e., the motivations that lead companies to make sure.

Findings: The results show that only four questionnaire items are sufficient to predict if a firm is certified or not. It is shown that companies in which the respondent manifests greater concern with respect to customers relations; motivations of the employees and strategic planning have higher likelihood of being certified.

Research implications: the reader should note that this study is based on data from a single country and, of course, these results capture many idiosyncrasies if its economic and corporate environment. It would be of interest to understand if this type of analysis reveals some regularities across different countries.

Practical implications: companies should look for a set of practices congruent with total quality management and ISO 9000 certified. 
Originality/value: This study contributes to the literature on the internal motivation of companies to achieve certification under the ISO 9000 standard, by performing a comparative analysis of questionnaires answered by a sample of certified companies and a control sample of companies which have not been certified. In particular, we assess how the manager's perception on the intensity in which quality practices are deployed in their firms is associated to the likelihood of the firm being certified.

Keywords: Quality; ISO 9000; decision trees, performance

JEL Codes: L15, L25, M1, M11

\section{Introduction}

Nowadays, quality is an element for the competitiveness and possibly one of the variables that has been influencing the conduct of managers, which has contributed to meet the demands of the contexts in which organizations perform their activities. In this sense, quality management has been revealing itself over time as a competitive advantage for organizations that have opt for it. The competition has led companies to revise their forms of organization, since increased competition prevents the marketing of products and services without quality. The Total Quality philosophy has been evolving since its appearance in the early $20^{\text {th }}$, century as companies feel the need to increase their level of competitiveness within the market in order to secure their continuity. This has been driven by increasingly globalized markets which in turn bring greater competences into the entrepreneurial environment and an increasing number of customers demanding higher quality product (Texeira-Quirós, Almaça \& Justino, 2010b). However, to ensure the quality, the organization must comply with various planned actions, which provide some confidence that a product or service meets the quality requirements. There are different systems to ensure quality, but the internationally recognized is the one which corresponds to ISO 9000, i.e., a rule aimed to certify the Quality Management System of a company.

The family of ISO 9000 standards are benchmarks for the implementation of quality management systems, which represent an international consensus on good management practices with the aim of ensuring the supply of products that meet customer requirements and with a focus on a continuous improvement. In this sense, standards are the basis for design, implementation, evaluation, specification and certification of quality systems, presenting a common international language. This also being a requirement for companies to remain in the market. Because of its growing widespread acceptance, ISO 9000 is becoming an important factor in the international trade, almost an imperative for companies that export to the European Union (EU) where buyers often explicitly request ISO 9000 certification (Erel \& 
Ghosh, 1997; Texeira-Quirós, Almaça \& Justino, 2010a). In this sense and according to the ISO Survey 2009, the total number of certificates issued worldwide in accordance with ISO 9001 , was 1,064,785 in 178 countries, representing an increase of over 81953 certificates the previous year, or more than $8 \%$. China is the country with the highest number of certified companies. Interestingly, American companies do not seem interested in obtaining certification as their European competitors. Thus the number of certifications in the U.S. is lower than in countries like Italy, Japan, Spain, Russia, Germany, the UK and even India.

There are several published works about the motivations of companies to be certified under the ISO 9000 standard. According to Tsiotras and Gotzamani (1996), there are essentially four main reasons that explain why companies implement a total quality management and cost system: improving the company's image and reputation abroad, meeting foreign demand and market pressures, facilitating and simplifying procedures and contracts between the company and its customers, and ultimately increasing productivity and the company's internal control and existing systems of quality management that the company may have implemented. For Jones, Arndt and Kustin (1997), companies get certified because they consider themselves obliged to do so, however, companies which have a more developed concept of quality get more benefits.

Heras, Casadesús \& Garvin (2002), reveals a study conducted at 400 certified and noncertified companies, that only a minority of studies found that the cost or waste were reduced, suggesting that for most companies the quality has not improved as a result of quality certification. It is surprising that the only consistent benefit found is the increase in sales or market share. This benefit may be due to the benefits of marketing of the "badge of quality" to the detriment of customers and improvements in quality. In contrast, the few studies that used financial measures audited think that companies with quality certification have superior financial performance. Also per Jones et al. (1997), companies make sure on how to improve their internal processes, reduce costs, and improve quality and customer focus.

Other reasons are given by Abraham, Crawford, Carter and Mazota (2000) the reason companies are satisfied, i.e., the certification provides little guarantee of getting a great impact, unless it is accompanied with a change of leadership, communication and structure. On the other hand, Terziovski and Samson (1997) published one of the more rigorous studies, analysing this subject, whose objective was to test the relationship between ISO 9000 certification and organizational performance in the presence and absence of a total quality management (TQM) environment. The analysis was performed on a sample of 962 industrial companies in Australia and 379 from New Zealand and found that the ISO 9000 certification does not have a significantly positive organizational performance on its own. The authors say that the main motivation for companies to have a quality certification is the ability that certification has to open doors to new customers that would have been difficult to achieve 
without the quality certification. In this sense, Youngdahl and Kellogg (1997), examined the relationship between customer service, quality assurance, satisfaction and effort - all this in the perspective of the costs of quality - and found that the classification of costs to quality customer service and their relationship with both satisfaction and effort, provides important capabilities to the design and implementation of services. Thus, the cost of quality concept predicts that as quality increases the total cost of quality decreases (Hendricks \& Singhal, 2001). The internal and managerial motivation to adopt ISO 9000 often has a positive effect on the likelihood of a certified organization achieving a better-performing effectiveness configuration (Boiral \& Amara, 2009). Terziovski and Samson (1997) found that although ISO 9000 had little or no impact on company performance, it can contribute to organizational performance if a climate of change is created. However, leadership, management of people, and customer focus were the strongest significant predictors of performance (Samson \& Terziovski, 1999). Similarly, Sun (1999), found that TQM practices such as quality leadership, human resource development, and quality information contributed to an increase in customer satisfaction and business performance. For Casadesús and Giménez(2000), there is no doubt that the process of certification according to ISO 9000, provides an evolution in how to manage a company, the organization, communication and quality system, in general are the key to success in business management. It took a cultural change, which affected the whole organization, where continuous improvement has become a basic tool to advance business competitiveness.

In the literature, the comparison of questionnaires answered by certified and non-certified companies is usually performed using conventional Student's t-test (see, e.g., Gotzamani \& Tsiotras, 2001). Here, we compare the answers provided by certified and non-certified companies using a multivariate predictive model. Conceptually, there is a subtle difference between comparing answers with t-tests and multivariate (or univariate) predictive models. The former should be used when we conjecture that certification conducts to different responses to the questionnaire; the latter should be employed when we believe that the perception of the respondents towards the questionnaire items conducts to certification. That is, rather than asking whether certified companies provide responses that are statistically different from those provided by noncertified companies, we try to understand if these responses predict, or are associated to the likelihood of the firm being certified.

The aim of this paper is to analyze the responses of two groups of firms: a group of companies certified by ISO 9000 and another group of non-certified companies and attempt to establish a relationship between the responses of two groups of companies so as to see if the company is certified or not and what are the variables that influence whether the company is a certified or uncertified one. This paper is organized as follows. The next section describes the data used in 
the empirical study. Section 3 shows the classification tree models. Finally, section 4 concludes the paper.

\section{Data}

Our analysis uses data obtained through the IPAC (Portuguese Institute of Accreditation). The initial universe consisted of 1015 certified companies with a quality management system, accredited through NP EN ISO 9001, in a region of Portugal (Lisboa e Médio Tejo). Because many of these companies were corporate groups, NPOs, employment services and vocational training companies, the initial sample was reduced to 666 companies. We devised a structured questionnaire in order to assess the respondent's perception on the intensity in which different quality practices are implemented in the firms. An initial telephone contact was first made to the target companies in order to explain the nature of the research. Then, an introductory letter formalizing the request and the actual research questionnaire were sent by e-mail. In the end, we obtained 172 responses, corresponding to a response rate of $26 \%$.

The research design determined the inclusion in the questionnaire of seventeen statements that measure the intensity of different quality practices. The questionnaire is shown in the Appendix. The statements aimed to ascertain the respondents' opinions about the impact of quality elements on the activity and economic environment of their firms. The seventeen statements covered different elements of a quality management system: customers relations (statements 1, 2 and 3); process management (statements 5 and 6); human resources management (statements 8 and 9); quality costs (statements 10 to 15); strategic planning (statements 16 and 17); and suppliers relations (statements 4 and 7).

The Likert scale was used to measure how the companies in the survey perceived the questionnaire statements. The level of agreement or disagreement with the statements was encoded in an ordinal scale with five categories: 1: strongly disagree 2: disagree 3: neither agree nor disagree 4: agree 5: strongly agree.

Through the Cronbach's alpha scales we assessed the level of reliability in our study, since Cronbach's alpha determines the internal consistency or average correlation of items in a survey instrument to gauge its reliability. An acceptable Cronbach's alpha should be higher than 0,7 (see, e.g., Bland \& Altman, 1997). In this sense, for all scales the reliability coefficient is above 0.77 , which means that our measurement scales are reliable and valid.

\section{Classification tree models}

Decisions trees are nonparametric and nonlinear predictive models in which the original data set is recursively partitioned into smaller mutually exclusive subsets using a greedy search algorithm (Breiman, Friedman, Olshen \& Stone, 1984; Quinlan, 1986). Therefore, it is 
interesting to understand the relationship between certification and questionnaire responses using a model that does not require a priori the choice of a functional form for the expected value of the nominal variable. This task may be accomplished with nonparametric models, in which the relationship between the variable of interest and explanatory variables is not predetermined by the researcher but is derived from information provided by the data. A popular nonparametric model for predicting nominal variables is the classification tree (Breiman at al., 1984; Quinlan, 1986). In this approach, the original data set is recursively partitioned into smaller mutually exclusive subsets, and the models are represented by a sequence of logical if-then-else tests on the attributes of the observations. Suppose one has a set of observations (i.e., companies) described by a vector of attributes (i.e., questionnaire responses), and that these observations belong to each of two classes (i.e., certified companies and non-certified companies). The goal of a classification tree is to separate as well as possible the observations that belong to one class from those that belong to the other through a sequence of binary splits on the data. The algorithm begins with a root node containing all observations. Then, the algorithm loops over all possible binary splits in order to find the attribute and corresponding cut-off value which gives the best separation into one side having mostly observations from one class and the other mostly observations from the other.

How are the optimal attribute and cut-off value defined? Denote by $p$ the number of observations of one class and by $n$ the number observations of the other class contained in a given node. The entropy $E(p ; q)$ of that node is defined as:

$$
E(p, q)=-\frac{\mathrm{P}}{\mathrm{p}+\mathrm{n}} \log _{2}\left(\frac{\mathrm{p}}{\mathrm{p}+\mathrm{n}}\right)-\frac{\mathrm{n}}{\mathrm{p}+\mathrm{n}} \log _{2}\left(\frac{\mathrm{n}}{\mathrm{p}+\mathrm{n}}\right)
$$

Now, suppose that a given binary split of the data leaves $p 1$ and $n 1$ observations of each class in one daughter node, and $p 2$ and $n 2$ observations of each class in the other. The optimal splitting attribute and corresponding cut-off value are those that maximize the information gain, so:

$$
\text { gain }=E(p, q)-\frac{p_{1}+n_{1}}{p+n} E\left(p_{1}, q_{1}\right)-\frac{p_{2}+n_{2}}{p+n} E\left(p_{2}, q_{2}\right)
$$

Positive information gains result in reductions of entropy. Since the entropy characterizes the diversity of the population in a node, maximizing the information gain results in daughter nodes that are more homogeneous than the parent nodes.

This procedure is then repeated for the new daughter nodes until no further improvement in class separation is achieved or a stopping criterion is satisfied. Unsplit terminal nodes are referred by the figurative term of leaves, and are depicted by rectangles in the schemes representing decision trees (see figure 1 ). Starting from the root node, all observations are routed down the tree according to the values of the attributes tested in successive nodes and, 
inevitably, terminate their path in a leaf. In the end, observations are classified according to the most prevalent class in the leaf where they terminated their path. A comprehensive description of tree algorithms is beyond the scope of this paper. The reader is referred to Witten and Frank (2005) for technical details of the algorithms employed here.

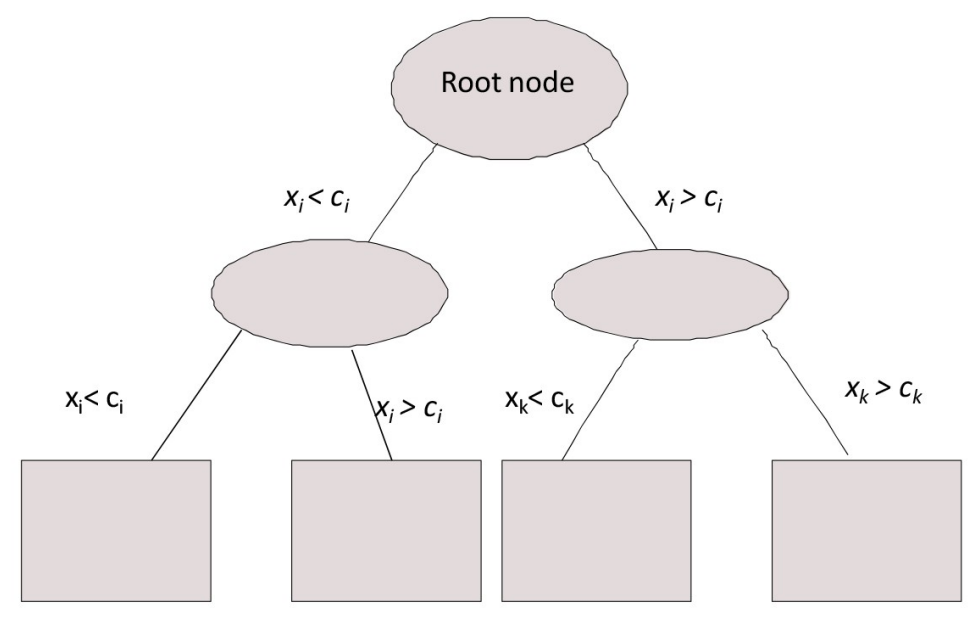

Figure 1. Simple scheme of a decision tree model. The model is represented by a sequence of logical if-then-else tests on the attributes of the observations. The terminal nodes, denoted by leaves, are depicted by rectangles

The figure 2 shows the classification tree model for the questionnaire responses and figure 3 for the six dimensions. The interpretation of these models is intuitive and straightforward. First, statement 3 asks the respondents opinion about "Along with market globalization, there was an increase in competitiveness, which resulted in more demanding customers." This statement assesses the respondent's perception towards the quality element "customers relations". The corresponding coefficient is positive, implying that higher values of the responses on the Likert scale are associated with certification. On the other hand, statement 9 ("Greater motivation of the employees provides an increase in commitment and individual responsibility towards the company.") measures the respondent's awareness with respect to human resources management. Statement 16 evaluates the opinion about "Strategic planning is a continuous process that generates the company's essential objectives. Those objectives should lead to a higher performance culture within the company.." Then, at the root node the model inquiries about the response to statement 16. If the response to statement 16 on the Likert scale is smaller or equal to 3 , then the model predicts that the company is not certified and the branch ends there. If the opposite occurs, the model then focuses on the response to statement 9. If the answer to this statement is smaller or equal to 3, the model again predicts that the company is not certified. If the contrary occurs, the model then inquiries about the response to statement 3 . If the response to statement 3 is greater than 4 , the model predicts that the company is certified. If the response to this statement is smaller or equal to 4 , the model finally inquiries about the response to statement 14 . If the response to this statement is 
smaller or equal to 3 , the model predicts that the company is non-certified; otherwise it predicts that the company is certified.

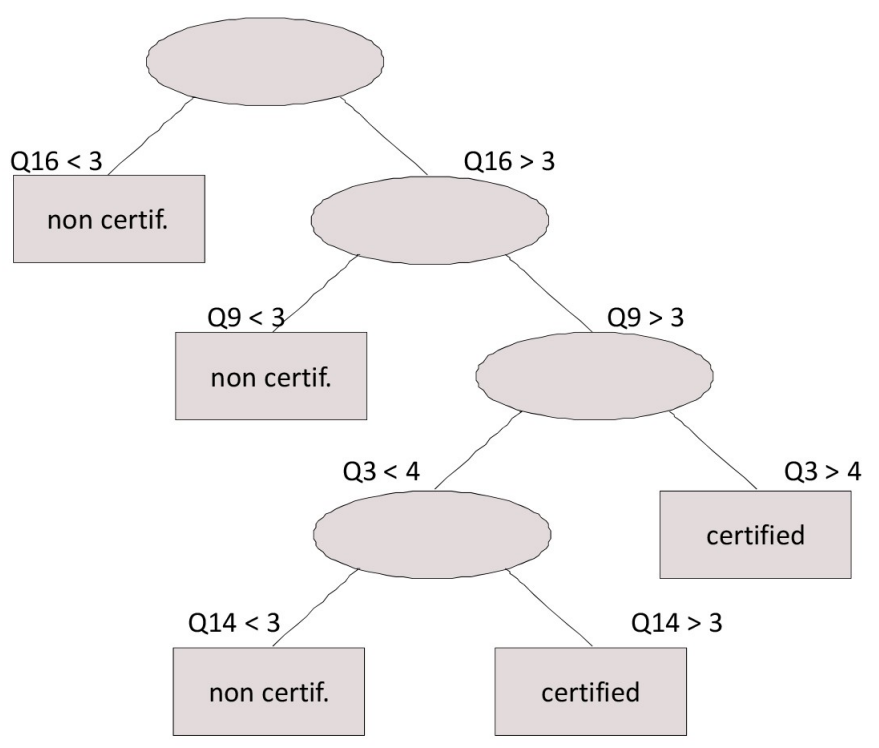

Figure 2. Classification tree model for questionnaire scales

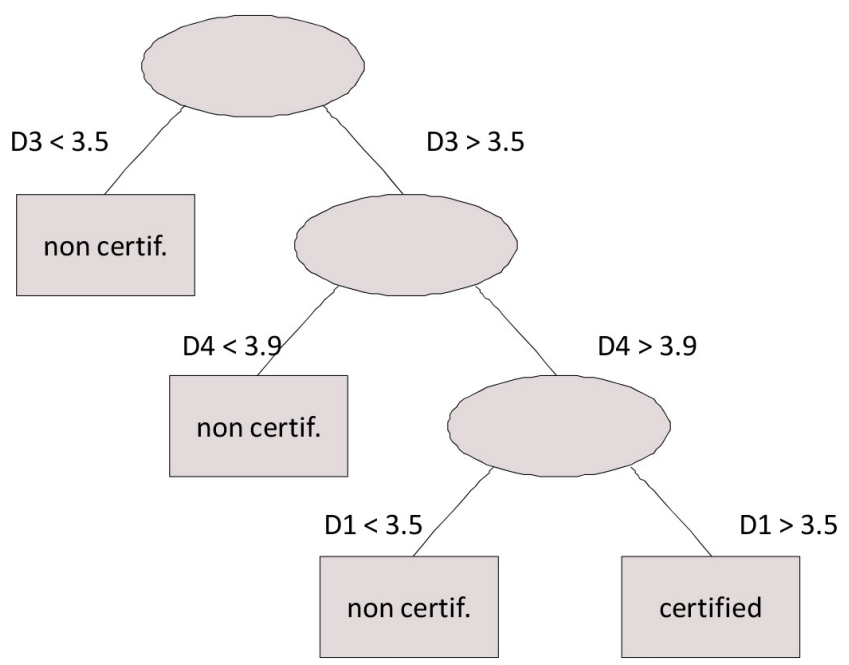

Figure 3. Classification tree model for questionnaire dimensions

The tree model found only Questions 3, 9, 14 and 16 were significant to associate the probability of certification. Furthermore, the tree model suggests that higher values on the Likert scale of these answers to the questions are associated to certification. However, the tree model also suggests that higher values of answers to statement 14 are associated to certification. This question asks the respondent's opinion on "Administrators actually know how much the company may lose by lack of quality.", which evaluates the perception towards the element "quality costs". Although these relevant differences have arisen related with "Administrators actually knowing how much the company may lose by lack of quality", in all 
other items (Q10, Q11, Q12, Q13 Q15) concerning the size "quality costs" there is no significant difference. We can say that although the analysis, measurement and adequate control of quality costs, contribute to prevent that making decisions are based on misinformation, which could lead to failure of the products or services in the market.

Although quality cost management is vitally important, we believe that often the administration is not aware of its economical incidence. If these costs were systematically measured, they could be systematically administered and that measurement provides a significant leadership of the quality's value, as well as of the growth of its profitability. This analysis is consistent with Sower and Quarles (2007), who prepared a study on 3200 companies, members of the ASQ Quality Management Division. Although it is crucially important to measure and control the costs of quality, there is little correlation between the data reported by the financial and quality departments, low participation of the finance departments in calculating the costs of quality and not understanding the impact of the cost on total spending. The authors also suggested that the reason companies do not control the costs of quality, is due to the lack of support from administration, the perception of lack of knowledge of the usefulness of these costs.

This tree structure allows us to draw the following conclusions. First, small values in response to statement 16 are associated to non-certified companies, since the branch Q16 $\leq 3$ leads to a "non certified" leaf. For the same reason, small values in response to Question 9 are also associated to non-certified companies. Large (small) values in responses to statements 3 and 14 are associated to (non-)certified companies, since conditions Q3 > 4 and Q14 > 3, respectively, lead to "certified" leaves. The remaining questions are not relevant since they are not presented in the tree structure. Interestingly, all statements related to the quality elements suppliers relations, process management are not significant in explaining the likelihood of certification.

\section{Conclusions}

The aim of this article was to analyse the responses from a questionnaire answered by ISO 9001 certified and non-certified companies, in order to assess if there are significant differences between the two groups. Conceptually, there is a subtle difference between comparing answers with t-tests and multivariate (or univariate) predictive models. The former should be used when we conjecture that certification conducts to different responses to the questionnaire; the latter should be employed when we believe that the perception of the respondents towards the questionnaire items conducts to certification. That is, rather than asking whether certified companies provide responses that are statistically different from those provided by noncertified companies, we try to understand if these responses predict, or are associated to the likelihood of the firm being certified. 
The ISO 9000 family of standards are benchmarks for the implementation of systems of quality management, which represent an international consensus on good management practices with the aim of ensuring the supply of products that meet customer requirements and focus on continuous improvement. They are also a basis for the design, implementation, evaluation, specification and certification of quality systems, introducing a common language internationally. It is also now an essential requirement for a company to stay in the market.

The results show that variables like, customer's relations, human resource management, strategic quality planning, and even quality costs are most important than supplier's relations and process management.

Thus, the main findings of the research are: by using nonparametric decision trees, and similarly to the previous point, there are differences in the items that comprise, customer's relations; human resource management and strategic quality planning. However, we must highlight the item related to the costs of quality, although they are utmost important, administration are often not aware of its economic impact.

As the company implements a totally oriented quality management system, it affects all its employees from the beginning, that is, to produce at the minimum possible cost products or services that meet customers' needs and that motivate the company's employees. Calculating quality costs allows an assessment of the programs implemented in companies.

\section{References}

ABRAHAM, M.; CRAWFORD, J.; CARTER, D.; MAZOTA, F. (2000). Management decisions for effective ISO 9000 accreditation. Management Decision, 38(3): 182-193. http://dx.doi.org/10.1108/EUM0000000005346

BOIRAL, O., AMARA, N. (2009). Paradoxes of ISO 9000 performance: A configurational Approach. Quality Management Journal, 16(3): 37-60.

BLAND, J.M.; ALTMAN, D.G. (1997). Statistics notes. Cronbach's alpha. British Medical Journal, 314: 572. http://dx.doi.org/10.1136/bmj.314.7080.572

BREIMAN, L.; FRIEDMAN, J.H.; OLSHEN, R.A.; STONE, C.J. (1984). Classification and regression trees. Wadworth International Group, Belmont, California

CASADÉSUS, M.; GIMÉNEZ, G. (2000): The benefits of the implementation of the ISO 9000 standard. Empirical research in 288 Spanish companies. The TQM Magazine, 12(6): 432-441. http://dx.doi.org/10.1108/09544780010351751

EREL, E.; GHOSH, G.B. (1997). ISO 9000 implementation in Turkish industry International. Journal of Operations and Production Management, 17(12): 1233-1246. http://dx.doi.org/10.1108/01443579710182972 
GOTZAMANI, K.; TSIOTRAS, G. (2001). An empirical study of the ISO 9000 standards' contribution towards total quality management. International Journal of Operations \& Production Management, 21(10): 1326-1342. http://dx.doi.org/10.1108/EUM0000000005972

HENDRICKS, K.B.; SINGHAL, V.R. (2001). Firma Characteristics, total quality management and financial performance. Journal of operations management, 19: 269-285. http://dx.doi.org/10.1016/S0272-6963(00)00049-8

HERAS, I.; CASADESÚS, M.; GARVIN, P.M. (2002). ISO 9000 Certification and the bottom line: a comparative study of the profitability of Basque region companies. Managerial Auditing Journal, 17(1/2): 72-78. http://dx.doi.org/10.1108/02686900210412270

JONES, R.; ARNDT, G.; KUSTIN, R. (1997). ISO 9000 Among Australian companies: Impact of time and reasons for seeking certification on perceptions of benefits received. International Journal of Quality and Reliability Management, 14(7): 650-660. http://dx.doi.org/10.1108/02656719710173258

QUINLAN, J.R. (1986). Induction of decision tees. Machine Learning, 1: 81-106. http://dx.doi.org/10.1007/BF00116251

SAMSON, D.; TERZIOSVKI, M. (1999). The relationship between total quality management practices and operational performance. Journal of Operations Management, 17: 393-409. http://dx.doi.org/10.1016/S0272-6963(98)00046-1

SOWER, V.; QUARLES, R. (2007). Costs of quality usage and its relationship to quality system maturity. International Journal of Quality \& Reliability Management, 24(2): 121-140. http://dx.doi.org/10.1108/02656710710722257

SUN, H. (1999). Diffusion and contribution of total quality management: an empirical study in Norway. Total Quality Management, 6(6): 901-914. http://dx.doi.org/10.1080/0954412997316

TERZIOVSKI, M.; SAMSON, D.(1997). The business value of quality management systems certification: Evidence from Australia and New Zealand. Journal of Operations Management, 15: 1-18. http://dx.doi.org/10.1016/S0272-6963(96)00103-9

TEXEIRA-QUIRÓS, J.; ALMAÇA, J.; JUSTINO, M.R. (2010a). How quality affects the bottom line? XXIV Congreso Anual European Association of Management and Business Economics (AEDEM) - Santiago de Compostela. ISBN: 978-84-7356-702-2.

TEXEIRA-QUIRÓS, J.; ALMAÇA, J.A.; JUSTINO, M.R. (2010b). How quality affects the bottom line?: A literatura review. Intangible Capital, 6(2): 258-271. http://dx.doi.org/10.3926/ic.2010.v6n2.p258-271

TSIOTRAS, G.; GOTZAMANI, K. (1996). ISO 9000 as na entry key to TQM: The case of Greek industry. International Journal of Quality, 13(4). 
WITTEN, I.H.; FRANK, E. (2005). Data mining: practical machine learning tools and techniques. Morgan Kaufmann Publishers.

YOUNGDAHL, W.; KELLOGG, D. (1997). The relationship between service customers quality assurance behaviors, satisfaction, and effort: A cost of quality perspective. Journal of Operations Management, 15: 19-32. http://dx.doi.org/10.1016/S0272-6963(96)00097-6

\section{Appendix}

Mark your level of agreement or disagreement with the following statements.

\begin{tabular}{|c|c|}
\hline 1. As a quality management system is implemented, it is perceived by its customers. & 12345 \\
\hline 2. It is easier to get your customers' loyalty by being a company with quality certification. & 12345 \\
\hline $\begin{array}{l}\text { 3. Along with market globalization, there was an increase in competitiveness, which resulted in } \\
\text { more demanding customers. }\end{array}$ & 12345 \\
\hline 4. The search for quality of your products frequently requires the search for new suppliers. & 12345 \\
\hline 5. There is the need to reduce the development period of new products or services. & 12345 \\
\hline 6. Increasing the internal link between activities improves the integration of different departments & 12345 \\
\hline $\begin{array}{l}\text { 7. Innovative products of higher quality should be introduced, relocating industrial products of } \\
\text { intensive labor to countries where labor force is cheaper. }\end{array}$ & 12345 \\
\hline $\begin{array}{l}\text { 8. The increase of individual qualification of the company's employees produces an impact on your } \\
\text { products in terms of quality and cost. }\end{array}$ & 12345 \\
\hline $\begin{array}{l}\text { 9. Greater motivation of the employees provides an increase in commitment and individual } \\
\text { responsibility towards the company. }\end{array}$ & 12345 \\
\hline 10. The company's quality costs should be controlled and distinguished from other costs. & 12345 \\
\hline $\begin{array}{l}\text { 11. The wrong idea that quality necessarily implies high cost is a relevant obstacle towards the } \\
\text { establishment and consolidation of quality programs. }\end{array}$ & 12345 \\
\hline $\begin{array}{l}\text { 12. Control and measure of quality costs should have a place in the company's management, under } \\
\text { the responsibility of the management accounting. }\end{array}$ & 12345 \\
\hline $\begin{array}{l}\text { 13. The quality costs for promotion of the company as an instrument of execution, planning and } \\
\text { control should be measured. }\end{array}$ & 12345 \\
\hline 14. Administrators actually know how much the company may lose by lack of quality. & 12345 \\
\hline 15. There may be a failure in the control of quality costs, as they might be miscategorized. & 12345 \\
\hline $\begin{array}{l}\text { 16. Strategic planning is a continuous process that generates the company's essential objectives. } \\
\text { Those objectives should lead to a higher performance culture within the company. }\end{array}$ & 12345 \\
\hline $\begin{array}{l}\text { 17. Performance assessment and stronger strategic alliances, developing new business areas in } \\
\text { main competencies, should be improved. }\end{array}$ & 12345 \\
\hline
\end{tabular}

1: strongly disagree; 2 : disagree; 3 : neither agree nor disagree; 4: agree; 5: strongly agree.

(C) Intangible Capital, 2013 (www.intangiblecapital.org)

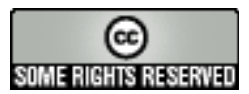

El artículo está con Reconocimiento-NoComercial 3.0 de Creative Commons. Puede copiarlo, distribuirlo y comunicarlo públicamente siempre que cite a su autor y a Intangible Capital. No lo utilice para fines comerciales. La licencia completa se puede consultar en http://creativecommons.org/licenses/by-nc/3.0/es/ 